\title{
Stylistic Analysis of Invocation in Alexander Pope's The Rape of the Locke
}

\author{
Abid Hayat Khokhar (Corresponding author) \\ Community College, Majmaah University, Saudi Arabia \\ E-mail: abidhayatkhokhar@hotmail.com \\ M. Athar Khurshid \\ Higher Education Department, Government of the Punjab, Pakistan \\ Hafizoah Kassim \\ Center of Humanities and Modern Languages, University Malaysia Pahang, Malaysia
}

Received: 04-01- 2015

Published: 01-09- 2015
Accepted: 06-03- 2015

doi:10.7575/aiac.ijalel.v.4n.5p.21
Advance Access Published: April 2015

URL: http://dx.doi.org/10.7575/aiac.ijalel.v.4n.5p.21

\begin{abstract}
This paper presents the stylistic analysis of the invocation part of The Rape of the Locke. The researcher has tried to uncover the mystery of the beauty of the lines of this mock epic. He studied the role of deviation, parallelism, and other factors, to determine the reasons of the poetic impact. The researcher found that the poet achieved the never ending praise for his work by making his individual lines impressive. These lines have been beautified by the skillful use of the techniques of deviation and parallelism. In addition to it, subtle ways of maintaining cohesion and coherence enhance the charm of the lines.
\end{abstract}

Keyword: deviation, parallelism, verbal repetition, text, discourse, lexis, syntax, foregrounding

\section{Introduction}

Stylistic analysis describes how does a language user enhance the impact of the text and discourse with the help of hidden and indirect clues. Now, this type of analysis is widely applied to literary and non-literary text. The researcher wanted to see through the mystery of his favorite poem "The Rape of the Locke". His project goes on but the present paper demonstrates his approach and the manner of analysis.

This paper describes the poet's technique of getting the attention of his reader and his manner of presenting the message. His techniques of embellishing the individual lines and the whole message have been described.

\section{Literature Review}

The review of literature consists mainly of the basic terms and concepts of Stylistics so that the system of stylistic analysis can be described.

\subsection{Poetic License}

Leech (1969) uses a term of poetic license for the poetic traditions. These traditions, usually, manifest themselves in lexis, syntax, and unusual way of twisting meanings. The phonetic, morphemic, syntactic structures which might look funny or absurd in ordinary language become acceptable in poems. They might have been constrained by the metrical or thematic requirements, but they are identified as the part of the poetic tradition. We anticipate them when we are about to read a poem.

\subsection{Foregrounding}

The poets catch the attention of the reader by defamiliarization (Childe and Fowler 2006, p. 93). Stylisticians use an alternative term for this process which is foregrounding (Leech, 1969; Short, 1996). It consists of deviation and parallelism. The examples of the former are: graphological deviation, lexical deviation, grammatical deviation, semantic deviation, phonological deviation, discourse deviation (Short, 1996).

\subsubsection{Graphological Deviation}

This refers to the unusual use of punctuation item. Cumming's poetry displays this deviation quite often. For example, view the following lines of E. E. Cumming:

anyone lived in a pretty how town

(with up so floating many bells down)

spring summer autumn winter

he sang his didn't he danced his did. (Cumming, 1991, p. 515) 
In the above stanza, each line, even the very first line of the poem, begins with letters in lower hand. In the above lines, 'anyone' is synonymous with 'a man'. This expression has been used to foreground generality of 'the man' referred to. Using the lower case in beginning of the first line of the poem further emphasizes the man's 'no manliness'.

\subsubsection{Lexical deviation}

Lexical deviation refers to nonce-formation or neologism. It means use of new words. New words are coined either by introducing a/the new morpheme/s or by affixing two known morphemes in an unprecedented combination. The example of the former is 'pandemonium' (Milton, 2005, p. 3); and that of the latter is 'manunkind' (cumming, 1991, p. $554,1.1)$. Usually, the latter are more frequently used in poetry. Leech $(1969$, p. 43$)$ quotes a line:

The unchilding, unfathering, widow-making deep

In the above-quoted line, lexical deviation occurs in three ways: (1) by adding an unexpected prefix un- to two nouns, (2) by transforming the nouns into verbs, (3) by making an unexpected combination of the two free morphemes.

\subsubsection{Syntactic Deviation}

Sometimes, the sentence structure of a poetic line deviates from the rules of grammar. This may be because of two reasons: (1) to maintain metrical rhythm; (2) to shift the theme rheme structure ${ }^{1}$. Read the following poem:

John Gilpin was a citizen

Of credit and renown,

A train-band captain eke was he

Of famous London town.

John Gilpin's spouse said to her dear,

'Though wedded we have been

These twice ten tedious years; yet we

No holiday have seen.'
(SVC)

(Leech, 1969, p. 18)

The underlined text of the poem displays deviation from the usual syntactic order i.e. SVO/C. The purpose of this deviation, in addition to the need of ordering the text in metrical pattern, may be avoiding the alternative structures which are ordinary and uninteresting. If these lines are put straight; they will instantly lose the charm.

\subsubsection{Semantic Deviation}

Semantic deviation refers to the use of metaphor and other figures of speech. The images used in the figure of speech suggest two layers of meanings: (1) superficial meanings and (2) actual meanings. Leech (1969) describes the former as either absurd or redundant. The contrast between the apparent absurdity or redundancy and the hidden wit surprises the reader; as a result, the related text becomes foregrounded.

\subsection{Parallelism}

The deliberate repetition of an item for an artistic effect is called parallelism (Leech, 1969; Short, 1996). They are of three types:

- Phonological Parallelism

- Syntactic Parallelism

- Lexical Parallelism (Verbal Repetition)

\subsubsection{Phonological Parallelism}

The core concepts of the phonological parallelism are based on the stressed syllable. Leech (1969, p. 63) has described the stressed syllables with the help of the following formula:

$$
\left(\mathrm{C}^{0-3}\right) \mathrm{V}\left(\mathrm{C}^{0-4}\right) \text {. }
$$

$\mathrm{C}$ represents the consonant cluster ${ }^{2}$; V represents the vowel; the post scripted digits ${ }^{0-3}$ and ${ }^{0-4}$ represent the strength of the cluster; and the parentheses represent the optionality of the enclosed items. Now, it turns out that an English stressed

\footnotetext{
${ }^{1}$ Halliday (2004) gave the theory of information packaging. According to this theory the theme of the clause is placed first and the rest of the clause or rheme serves to inform about the theme. It is not necessary only subjects NPs are used as themes. Adverbs, Dummy subjects, and even object NP may be used as themes.

${ }^{2}$ A consonant cluster is a chain of consonants only, without any vowel. In a stressed syllable, they may occur at two positions: the pre vowel and post vowel slots. The former is called onset and the latter coda. Onset may carry nil to three consonants; while in coda, nil to four consonants may exist. The presence of consonants is only optional; while the presence of one vowel is mandatory. For this reason, consonants are enclosed in the parenthesis above. Parentheses represent optionality.
} 
syllable consists of an obligatory vowel nucleus, and two optional consonant clusters whose strengths may vary from zero to three in the onset position, and zero to four in the coda position.

The stressed syllable may consist of three fragments. Leech (1969) and Short (1996) calls the deliberate, artistic repetition of any one or two of them phonological parallelism; if all the three fragments are repeated, Leech calls them the example of verbal repetition (also lexical parallelism). The examples of the phonological parallelism are:

Alliteration:

$$
\begin{aligned}
& \text { dream drink } \\
& \text { /dr i: } \mathrm{m} / \quad / \mathbf{d r} \quad \mathrm{I} \quad \mathrm{jk} / \\
& \text { C } \mathrm{V} \text { C } \quad \text { C } \mathrm{V} \text { C }
\end{aligned}
$$

Assonance:

dream feel

$\begin{array}{llllll}/ \mathrm{dr} & \mathbf{i}: & \mathrm{m} / & / \mathrm{f} & \mathbf{i}: & \mathrm{l} / \\ \mathrm{C} & \mathbf{V} & \mathrm{C} & \mathrm{C} & \mathbf{V} & \mathrm{C}\end{array}$

Conssonance:

dream roam

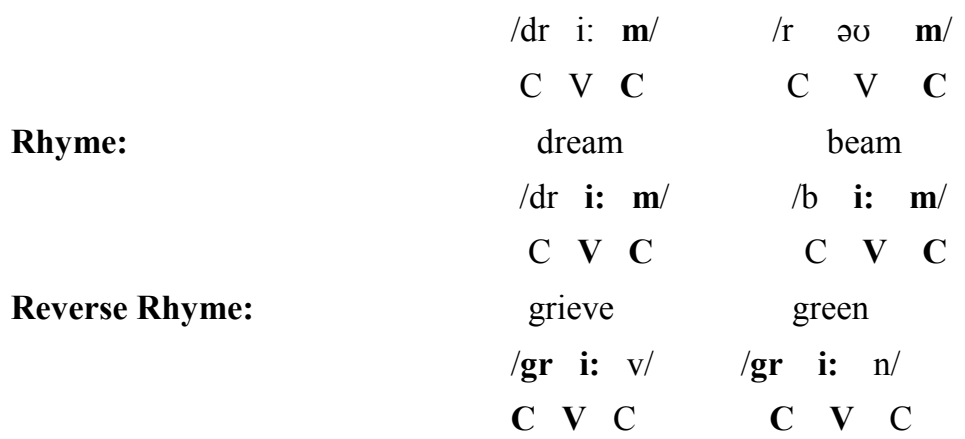

Para Rhyme:

\begin{tabular}{cccccc}
\multicolumn{3}{c}{ dream } & \multicolumn{3}{c}{ drum } \\
$/ \mathbf{d r}$ & i: & $\mathbf{m} /$ & $/ \mathbf{d r}$ & $\Lambda$ & $\mathbf{m} /$ \\
$\mathbf{C}$ & $\mathrm{V}$ & $\mathbf{C}$ & $\mathrm{C}$ & $\mathrm{V}$ & $\mathbf{C}$
\end{tabular}

\subsubsection{Syntactic Parallelism}

The repetition of the same sentence structure but not the same wording is called syntactic parallelism. For example,

$$
\text { He came; he saw; he conquered. }
$$

In the above sentence, three clauses are written in the same mood. The repetition of the sentence structure or that of the phrase structure is termed as syntactic parallelism. Such repetitions foreground the text and the idea contained in it (Leech, 1969; Short, 1996).

\subsubsection{Lexical Parallelism}

This refers to the repetition of a word, phrase, or a clause in a regular pattern. Leech (1969) describes these patterns as follows:
Anaphora:
(a...........)
$(\mathrm{a} . . . . . . . .$.
(Leech, 1969, p. 80)
Epistrophe:
$(\ldots \ldots \ldots \ldots . . . a)$
(............a)
Symploce:
(a..........b)
$(\mathrm{a} . \ldots \ldots \ldots . . . \mathrm{b})$
Anadiplosis:
a) (
(Leech, 1969, p. 81)
Epanalepsis:
a) (b.
..b)
Antistrophe:
(a.
...b......)
(Leech, 1969, p. 82)

Polyptoton. 'The repetition of a word with varying grammatical inflections. For example,

'And singing still dost soar, and soaring ever singest.' 
Homoioteleuton. 'The repetition of the same derivational or inflectional ending on different words' (Leech, 1969, p. 82). For example,

'The yellow fog that rubs its back upon the window-panes,
The yellow smoke that rubs its muzzle on the window-panes'

(Leech, 1969, p. 83)

\subsection{Discourse}

Verdonk (2002, p. 18) describes discourse as 'the process of the activation of text by relating it to a context of use'. The term 'discourse' has been defined variously; but the present concept of discourse has sustained in Stylistics from Widdowson (1975) who took it as the communicative use of language.

The above definition of discourse suggests that part of the meaning of a message is contributed by its linguistics features, and part by the context.

\subsection{Text}

A text may be meaningful in the absence of a context, but it will not carry any message. For example, a sign board with the text 'No Parking' will carry no message if you find it lying in a store, though it shall have some meanings. If the same sign board is installed on a road side, it will carry a message.

So, an 'intended message' is discourse; while a text, without context, may be meaningful but it carries no message. In Stylistic study, the work is analysed on two levels:

1. as an example of discourse;

2. and as an example of text.

\subsubsection{Superimposition of Style on Discourse}

In the analysis of a work as an example of discourse, a writer's individuality in shaping the message is studied. For example, what discourse markers they use? How do they organize their contents? Do they address directly or indirectly? Do they use symbols or write plain meanings? Do they appeal to aesthetic sense or to reason? Such questions are answered in describing an author's discourse style.

\subsubsection{Superimposition of Style on Text}

A writer's individuality or style in the text is studied in his choice of lexis and his sentence structures. Every person has a set of expressions which he uses more frequently than others; every writer draws his figures of speech from different sections of life. Every writer shapes his sentences differently: some use cleft sentences; some use heavy pre or post modification; some use simple sentences. In this way, grammatical structures reflect writer's individuality of the style.

Bilal and Cheema (2012) analysed Wordsworth's poem "Early Spring". They have mainly depended on the factors of parallelism and deviation for their analysis. Their main emphasis is on identifying the different stylistic features present in the work. They have not described in detail the communicative use of those features. The researcher of the present study has tried not to leave this gap.

McIntyre (n.d.) ${ }^{3}$ analyses E.E. Cumming's style in "Listen". In addition to describing the factors of parallelism and deviation, he makes a table of key lexical items and describes their function in the discourse. The researcher of the present study plans to make a table of the stylistic technique and observe their impact on the overall message.

\section{Methodology}

The author plans to analyse the Invocation part of the Rape of the Locke by observing the role of Lexical Deviation, Morphological Deviation, Graphological Deviation, Syntactic Deviation, Semantic Deviation, Syntactic Parallelism, Phonological Parallelism, and Verbal Repetition on the text of the above mentioned poem. In addition to these, the researcher also wants to study the poet's style at discourse level in order to know how he made a masterpiece out of a trivial incident.

\section{Stylistic Analysis}

The title of the poem is the combination of a striking and a trivial image i.e., 'rape' and 'lock'. The same contrast continues in the coming lines.

Line 1 WHAT dire offence from am'rous causes springs,

Cognitive Meanings. To how dreadful consequences romantic gestures may lead!

To say that the paraphrase of the above line communicates its fullest meaning would be unjust. The paraphrase contains only surface and literal meanings. It does not express the impressions left by the indirect clues. Those clues have been analysed one by one:

\footnotetext{
${ }^{3}$ This citation is based on an unpublished article displayed on the Lancaster University website, as mentioned in the reference section below. The date of the article is not given. APA allows writing (n.d.), if the date of the work is not available.
} 
Graphological Deviation: 'WHAT'. All letters are in upper case. This Graphological deviation foregrounds the meaning of 'what'. It has been foregrounded because the answer to this 'what' is the theme of the present poem.

Syncope. In another instance, /o/ has been dropped from 'am'rous'. This reduces the number of syllables from three to two; and one of two unstressed syllables is dropped. This technique is called Syncope (Leech, 1969, p. 18).

Syntactic Deviation: Hyperbaton: SAV. The Adjunct 'from am'rous causes' has been preposed. This provides a contrast of 'dire' and 'am'rous' and humour is created. This combination agrees with the title of the poem.

Phonological Parallelism: Consonance. Loose consonance of /s/ in 'offence' and 'am'rous', and / $\mathrm{z} /$ in 'causes' and 'springs' creates a musical effect which foregrounds the contents and, as a result, it catches the attention of the reader more effectively.

Line 2 What mighty contests rise from trivial things,

Cognitive meaning. How much fuss is created from ordinary disputes!

Verbal Repetition: Anaphora: What. This pattern of verbal repetition is called anaphora (Leech, 1969, p. 80). This repetition strengthens effect of Exclamation produced by the first 'WHAT'. Its psychological impact on the minds of the readers is that it does not let them change their focus. In this way, it creates a cohesive effect in the text.

Phonological Parallelism: Assonance. Two examples of assonance can be noted in the line: (1) $/ \mathrm{m}$ ar tI ...... r aI z/

(2) /tr I viəl $\quad \theta \mathbf{I} \mathrm{gz} /$ These two occurrences seem to be coincidental because no idea has been foregrounded.

Syntactic Parallelism. Line 1 and 2 raise two questions in the interrogative mood of the present simple tense. The parallel structure sustains the tone and enhances cohesion.

Line 3 I sing - This verse to Caryll, muse! is due:

Cognitive meaning Oh muse, I dedicate this poem to Caryll.

Discourse Style: Coherence: The main clause of the poem is 'I sing'. This is the meaning continuation of first two lines. This is the answer to the 'What' of the first two lines.

Graphological Deviation: 'muse!' In line 7, the mark of exclamation follows 'Goddess!' Here the poet addresses the muse. This analogy helps us to suppose that the poet addresses the 'muse!' in this line.

Semantic Deviation: Parody. The lexical items 'sing' and 'muse' are traditional to epic poetry. In paradise lost, and in every other epic poem, they can be seen on the first page. Line 3 creates humour by adopting a very serious tone to narrate a trivial incident.

Semantic Deviation: Antithesis. The modifying clause stays as the antithesis of that of the first two lines. The light comedy of this line becomes intensified in contrast with the seriousness aroused by the first two lines.

Line 4 This, ev'n Belinda may vouchsafe to view

Cognitive meaning. Even Belinda may be kind enough to read it.

Tenor: Lexis. The lexical items 'may' and 'vouchsafe' suggest the high status of Belinda. Placing Belinda next to 'muse' also suggests the former's importance in the poem. Actually, here the muse foregrounds the importance of Belinda.

Lines 5, 6 Slight is the subject, but not so the praise

If she inspire, and he approve my lays.

Cognitive meaning. Though the subject matter of the poem is based on an ordinary incident; yet by the support and encouragement of Caryll and Belinda I hope to transform it into a masterpiece.

Discourse: Coherence: Justification. Now, to shed the comic effect of the previous lines, the poet adopts the serious tone and gives his justification of selecting a trivial theme.

Syntactic Deviation: pluralization. The plural verbs 'inspire' and 'approve' follow the singular subjects 'he' and 'she'. This suggests the princely status of the two characters.

Phonological Parallelism: Alliteration. The repetition of /s/ sound in 'subject' after 'Slight' further strengthens the collocation between the two. Moreover, the repetition of $/ \mathrm{p} /$ sound in the stressed syllables of 'inspire' and 'approve' further consolidates the semantic field created by this combination.

Phonological Parallelism: Rhyme. The rhyme between the line endings 'praise' and 'lays' is a traditional mode of ornamentation; but it serves an additional purpose, too. The missing singularity marker 's' in 'inspire' and 'approve' becomes psychologically compensated, though not grammatically, by its presence in 'lays'.

Lines 7, 8 Say what strange motive, Goddess! could compel

A well-bred Lord t' assault a gentle Belle?

Cognitive meaning. Oh Goddess! Tell me what extraordinary reasons forced a well-mannered lord to offend a tender, beautiful girl.

Discourse Deviation: Second person addressee. By introducing the second person addressee 'Goddess', the poet creates a sense of immediacy. The reader feels as if he were overhearing a conversation. 
Graphological Deviation: Goddess! The mark of exclamation on 'Goddess' gives the line life-like effect. It enhances the reader's feeling of overhearing a conversation.

Tenor: Cliches. The words like 'lord', 'Belle', 'assault' are almost the currency of epic poetry. 'Belle', instead of 'a girl' has a more powerful impression. The components of beautifulness and romance are traditionally associated with it.

Semantic Deviation: Parody: 'Say..... Goddess!'. This is the most frequently occurring combination in epic poetry. Actually, an epic poem is incomplete without it.

Syntactic Deviation. 'Goddess' is inserted between the subject and verb of the embedded clause. It is a clever example of information packaging. Both the subject and predicate have been foregrounded: the former by the precedence of 'Say' and the latter by that of 'Goddess'.

Phonological Parallelism: Assonance. In line 8, the assonance of /ei/ in 'say' and 'strange' unites them cohesively, if not semantically. The same effect is observable in the assonance of $/ \mathrm{p} /$ in 'what' and 'Goddess'. In line 9 , the assonance of /e/ can be observed in 'well', 'bred', 'gentle', and 'Belle'. Four times repetition of a vowel sound in a line foregrounds not only the repeated sound but also the message contained in that text.

Graphological parallelism: Apocope: t' assault. By poetic license (Leech, 1969, p. 36), the poets take liberty to deviate from the conventional rules. Here, Pope applies apocope (Leech, 1969, p. 18), and /tu:/ is contracted as /t/ to merge in 'assault' to result in a new combination /təss:lt/. In other words, three syllables have been contracted into two. The reason is to make one of two unstressed syllables.

Lines 9, 10 O say what stranger grounds, yet unexplor'd, Could make a gentle Belle reject a Lord?

Cognitive Meaning. (Oh muse), tell me about those further extraordinary and unknown circumstances which led a charming lady to reject the proposal of a noble lord.

Syntactic Deviation: Ellipsis: ' $O$ say'. This exclamation should have accompanied the title of the addressee, 'muse' in this case. But to avoid redundancy, the poet has skipped it. This instance of ellipsis helps to enhance cohesive effect. At the same time, the conversational tone is upheld to maintain the sense of immediacy.

Lines 11, 12 In tasks so bold can little men engage,

And in soft bosoms dwells such mighty rage?

Cognitive Meaning. (Oh muse tell me) how men come to undertake so big adventures; and what makes ladies of gentle temperament go mad?

Syntactic Deviation: Hyperbaton. In both the clauses, Adjunct PPs (Carnie, 2006, pp. 69, 161) have been preposed. In the first clause, where Adjunct PP is preposed, AdjP (Carnie, 2006, p. 66) is postposed. AdjP complements the NP instead of modifying it. In the second clause, Adjunct PP is preposed; the subject NP is postposed; the main verb is inverted to make a question. In this way, the first clause follows ASV structure, and the second clause follows AVS structure. The poet presents grammatical objects NP as themes (Halliday, 2004, p. 56) or the psychological subjects (Halliday, 2002, p. 189); while the grammatical subject and verb predicate the message and function as rheme (Halliday, 2002, p. 191; 2004, p. 64).

Syntactic Parallelism. The sentence consists of two clauses, in each Adjunct PP is preposed, (Carnie, 2006, pp. 69, 161). Both clauses are of the interrogative mood.

Tenor: Cliches. Some lexical items have poetic tradition. They are: 'bosom', 'dwel', 'mighty', and 'rage'. They are the predictable part of poetic lexis (Leech, 1969, pp. 15, 16). Their function here is to reinforce the poetic impression.

List of Stylistic Features

\begin{tabular}{|c|c|c|c|c|c|c|c|}
\hline & L2 & L3 & L4 & LL5,6 & LL 7,8 & $\begin{array}{l}\text { LL9, } \\
10\end{array}$ & $\begin{array}{l}\text { LL11, } \\
12\end{array}$ \\
\hline GD & $\begin{array}{l}\text { Upper Case } \\
\text { WHAT } \\
\text { Syncope } \\
\text { am'rous }\end{array}$ & $\begin{array}{l}\text { Exclamation } \\
\text { muse! }\end{array}$ & & & $\begin{array}{l}\text { Exclamati } \\
\text { on } \\
\text { Goddess! } \\
\text { Apocope } \\
\text { t'assault }\end{array}$ & & \\
\hline $\mathrm{SD}$ & $\begin{array}{l}\text { Hyperbaton } \\
\text { SAV }\end{array}$ & & & Pluralization & & $\begin{array}{l}\text { Ellipsi } \\
\text { s } \\
\text { O say }\end{array}$ & $\begin{array}{l}\text { Hyperb } \\
\text { aton } \\
\text { ASV, } \\
\text { AVS }\end{array}$ \\
\hline $\begin{array}{l}\text { MD } \\
\text { ND }\end{array}$ & & $\begin{array}{l}\text { Parody } \\
\text { Antithesis }\end{array}$ & & & $\begin{array}{l}\text { Parody } \\
\text { Say.. } \\
\text { Goddess }\end{array}$ & & \\
\hline
\end{tabular}




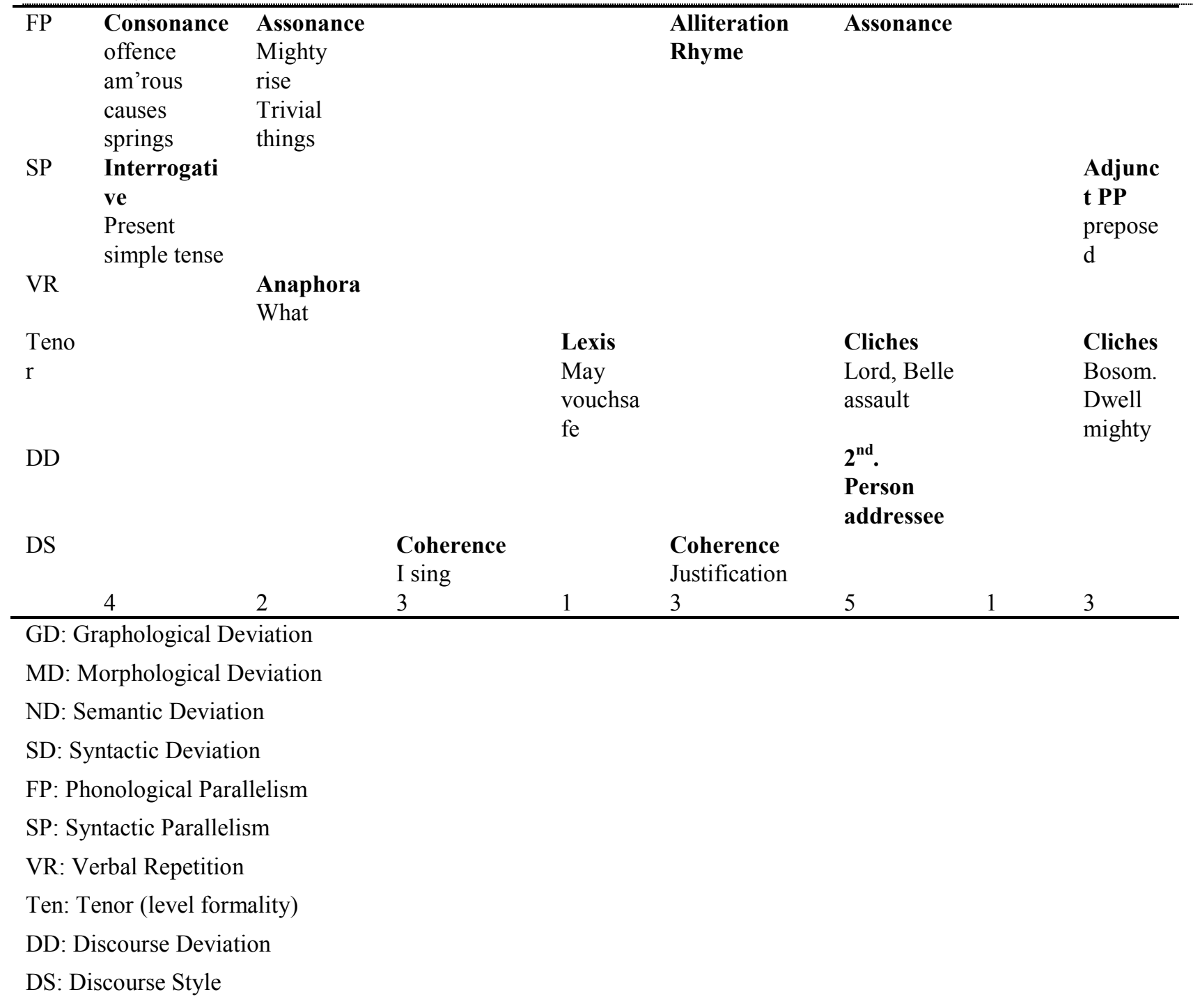

\section{Discussion and Conclusion}

In the above analysis and findings of the first 12 lines of invocation, the researcher discovered 22 factors which differentiate art from paraphrase. This is the authors' interpretation only. Other researchers may come up with many other points too.

Now in the end, the researchers will describe what style this above discourse follows. First, the stretches of cognitive meaning are put together and make a paragraph of the message of the lines under discussion. Next, I will point out how the style has been imposed on the discourse.

To how much dreadful consequence, romantic gestures may lead! How much fuss is created from ordinary disputes! Oh muse, I dedicate this poem to Caryll. Even Belinda may be kind enough to read it. Though the subject matter of this poem is based on an ordinary incident; yet by the support and encouragement of Caryll and Belinda, I hopes to transform it into a masterpiece. Oh Goddess! Tell me what extraordinary reasons forced a well-mannered lord to offend a tender, beautiful girl. (Oh muse), tell me about those further extraordinary and unknown circumstances which led a charming lady to reject the proposal of a noble lord. (Oh muse tell me) how men come to undertake so big adventures; and what makes ladies of gentle temperament go mad?

The first twelve lines of the poem are the introductory part of the poem and all of them are directly or indirectly related to the process of invocation. They can be divided into three parts: (L1, 2: theming); (L3-6: invocation); (L7-12: describing the issue). The first two lines are like a soliloquy. The reader is made to presume as if they were overhearing a talk. The message of L1 has been foregrounded with the help of graphological and syntactic deviations; phonological and syntactic parallelism. At least four techniques are applied on a single line. The reason is the effort to catch the reader's attention even at the very first word which is written all in upper case 'WHAT'. The line 2 carries only two techniques: phonological parallelism and verbal repetition. This is because the second line does not introduce any new theme; it merely echoes the theme of L1. Line 3 begins with the clause 'I sing' and all the following clauses are separated with the help of a dash. The invocation is made in the post dash clauses. The main clause 'I sing' serves to maintain the cohesive link between the first two lines and the third one. It is, as if, answer to the 'WHAT' of L1. In lines 3-6, he addresses the muse, dedicates the poem to Caryll, invites the attention of Belinda and Caryll, and acknowledges their support as the source of inspiration for him. He foregrounds these lines with the help of syntactic deviation and phonological parallelism but the most interesting factor is his discourse style, the way he creates cohesion 
and coherence among the lines by the use of a two word clause 'I sing'. Lines 7-12 are the elaboration of Lines 1 and 2. He links the line 7 with the previous lines by addressing the 'Goddess' whom he had mentioned in line 3 as 'muse'. In answer to the questions raised in LL1-2, he raises a few more questions. Through these newly raised questions he presents the subject matter of the story and requests the muse to enlighten him about the reason of these strange happenings. His manner of presentation is conversation like. The reader gets the impression as if he were overhearing a conversation. This technique enhances the reader's sense of immediacy. The poet unites the process of dedication and description of subject matter with invocation by his skilful use of cohesion and coherence, created by the use of 'I sing' and 'Say'. The mock grandeur of the lines has been maintained by the use of clichés, specific to epic poems; and by the use of exclamations in the manner of a dialogue. So, all the above mentioned techniques combine to create a mystery which is missing in the non-artistic language.

The above discussion points out the elements of style which make Rape of the Locke a masterpiece in spite of the fact that the theme it presents is quite ordinary and not more important than a news in a local newspaper. The manipulation of these elements into a polished poem is the art of a poet. In the poem generally, and the invocation particularly, the most dominating technique which reflects through most of the elements is the fusion of contrasts. Right from the title to the end of invocation part, the reader rocks between the serious and non-serious tones.

\section{References}

Bilal, A. H. and Cheema, M. (2012, May). Stylistic analysis of Wordsworth's poem Early Spring. British Journal of Humanities and Social Sciences, 5(2), 25-34.

Carnie, A. (2006). Syntax: A generative introduction (2 ${ }^{\text {nd }}$. Ed.). Maldan, MA: Blackwell.

Childe, P. and Fowler, R. (2006). The Routledge Dictionary of Literary Terms. Oxon: Routledge \& Kegan Paul Ltd.

Collin, P. \& Hollo, C. (2000). English grammar: An introduction. London: Macmillan Press Ltd.

Cumming, E. E. (1991). Pity this busy monster, manunkind. In George J. Firmage (Ed.), E. E. Cummings complete poems 1904-1962, (p. 554). New York, NY: Liveright.

Fabb, N. (2004). Language and Literary structure: The linguistic analysis of form in verse and narrative. Cambridge: Cambridge University Press.

Halliday, M. A. K. (2002). On grammar. London: Continuum.

Halliday, M. A. K. (2004). An introduction to functional grammar ( $3^{\text {rd }}$. Ed.). London: Arnold, a member of the Hodder Headline Group.

Leech, G. N. (1969). A linguistic guide to English poetry. Essex: Longman.

Milton, J. (2005). Paradise lost, Bk I. London: Dover Publication, Inc.

McIntyre, D. (n. d.). Doing stylistics: An analysis of 'listen' by E. E. Cummings. Retrieved (January 21, 2015) from Ling 131 Language \& Style is a Stylistics course within the Department of Linguistics and English Language (LAEL) at Lancaster University website: http://www.lancaster.ac.uk/fass/projects/stylistics/sa1/example.htm

Short, M. (1996). Exploring the language of poems, plays and prose. Essex: Addison Wesley Longman Ltd.

Simpson, P. (2004). Stylistics. London: Routledge.

Verdonk, P. (2002). Stylistics: A resource book for students. Oxford: Oxford University Press.

Widdowson, H. G. (1975). Stylistics and the teaching of literature. London: Longman Group. 